\title{
Healthy aging and age-adjusted nutrition and physical fitness
}

\author{
Mats Hammar and Carl Johan Östgren
}

\section{Linköping University Post Print}

\section{Tweet}

N.B.: When citing this work, cite the original article.

Original Publication:

Mats Hammar and Carl Johan Östgren, Healthy aging and age-adjusted nutrition and physical fitness, 2013, Baillière's Best Practice \&amp; Research: Clinical Obstetrics \&amp; Gynaecology, (27), 5, 741-752.

http://dx.doi.org/10.1016/j.bpobgyn.2013.01.004

Copyright: Elsevier

http://www.elsevier.com/

Postprint available at: Linköping University Electronic Press

http://urn.kb.se/resolve?urn=urn:nbn:se:liu:diva-100308 


\title{
Healthy aging and age adjusted nutrition and physical fitness
}

\section{Initiated Review}

\section{Hammar ${ }^{2}$, C.J. Östgren ${ }^{1}$}

${ }^{1}$ Department of Medical and Health Sciences, Faculty of Health Sciences, Linköping University, Linköping; Sweden

${ }^{2}$ Department of Clinical and Experimental Medicine, Faculty of Health Sciences, Linköping University, Linköping, Sweden

\author{
Corresponding author \\ Mats Hammar \\ Department of Clinical and Experimental Medicine \\ Linköping University \\ SE 58183 Linköping, Sweden \\ Phone +46 101033131 (office),+46 705293125(mobile) \\ E-mail: mats.hammar@liu.se
}

Word count: 4709 


\begin{abstract}
(154 words)
The expected life span is gradually increasing worldwide. For healthy ageing there are a number of options that may be used including healthy dietary and exercise habits. To reduce or prevent obesity certain types of diet may be used that will also reduce the risk of, e.g., cardiovascular disease (CVD). Exercise reduces the risk of diseases like CVD, osteoporosis, some cancers and some mental disturbances. Decreasing a sedentary life style seems at least as important as regular exercise. Exercise can probably be tailored to reduce the risk of CVD and extent of bone loss. To insure adherence, it is important to slowly increase the frequency, duration and intensity of exercise and to find activities that suit the individual. More research has to be done in order to find the ideal modes and doses of exercise and to increase long-term adherence. Both dietary and exercise modification seem to be strong promoters of healthy ageing.
\end{abstract}




\section{Introduction}

The oldest old are among the fastest growing segment of the population. It has been estimated that the number of centenarians will approach 3.2 million world-wide by 2050, a greater than 18 -fold increase from the turn of the 21st century [1]. Additionally, the World Health Organization estimates that by 2025,120 countries will have reached total fertility rates below the replacement level-compared to 22 countries in the 1970s [2]. With the increasing emphasis on health and the progressive lengthening of the average life span, there is a need for examining new ways to improve well-being and to prevent disease at every stage of life. Globally, cardiovascular disease (CVD) and cancer are the leading causes of mortality and loss of disability-adjusted life years [3].

As the population ages it is important to understand not only the impact of modifiable lifestyle factors such as diet, nutrition and physical fitness on the achievement of longevity but also the role of these factors in maintaining optimal cognitive, mental, and physical health into advanced age. This review summarizes current knowledge of age-adjusted nutrition and physical fitness in the elderly.

\section{Age adjusted nutrition}

\section{Obesity}

\section{Obesity and aging}

The rising percentage of obese individuals on a global scale has led the scientific community to seek to determine the causes for this increase and the factors causing the disease. Why do obese subjects eat more than the non-obese? Besides over-consumption of high-caloric foods, endocrine dysfunction and sedentary lifestyle, the hypothesis that food addiction is a leading cause for obesity is now being more widely accepted[4]. Furthermore, there is evidence that obesity-related behaviours (regarding both physical activity and diet) from childhood predispose adulthood behaviours [5]. However, both food choice and physical activity are modifiable behaviours and changing them to more healthful behaviours in childhood may lead to more healthful adult behaviours and accordingly to a reduced risk of obesity and of obesityrelated disease.

Data from large population studies show that mean body weight and body-mass index (BMI) gradually increase during most of adult life and reach peak values at 50-59 years of age in both men and women [6,7]. Aging is associated with considerable changes in body composition. After 20-30 years of age, fat-free mass progressively decreases, whereas fat mass increases. The fat-free mass decreases on average by up to $40 \%$ from 20 to 70 years of age [8]. The maximal fat-free mass is usually reached at 20 years of age, and the maximal fat mass is usually reached at 60-70 years of age; both measures subsequently decline thereafter [8]. Accordingly, both fat-free mass and fat mass decrease after the age of 70 years. Aging is also associated with a redistribution of body fat and with aging there is a greater relative increase in intra-abdominal fat than in subcutaneous or total body fat [9].

\section{Definition and adverse effects of obesity}

Obesity is still widely defined in terms of BMI, even though this is not the most accurate predictor of diabetes or vascular risk. BMI is a simple index derived from the weight-toheight ratio defined as weight in kilograms divided by the square of height in meters $(\mathrm{kg} / \mathrm{m} 2)$. This index is used to classify individuals as underweight (BMI $<18.5)$, normal weight (18.524.99), overweight (25.0-29.99) or obese ( $\geq 30.0)$, which are the most commonly used definitions, established by the World Health Organization (WHO) [10]. As Asian populations 
develop negative health consequences already at a lower BMI than Caucasians, some nations have redefined obesity; in Japan obesity has been defined as any BMI greater than 25 [11]while China uses a BMI of greater than 28 [12].

BMI is widely used in epidemiological studies, since measurements of height and weight are usually available, but BMI does not accurately reflect fat mass or fat distribution. Abdominal obesity is a well-established phenotypic companion of a cluster of metabolic abnormalities characterized by insulin resistance, and abdominal obesity is the best obesity-related predictor of type 2 diabetes [13]. Waist circumference is currently the most commonly used measure of abdominal obesity, and it is highly associated with CVD [14]. The International Diabetes Federation suggests ethnic-specific waist circumference cut-offs for the definition of central obesity [15]; Europids: men $\geq 94 \mathrm{~cm}$, women $\geq 80 \mathrm{~cm}$, South Asians and Chinese: men $\geq 90$ $\mathrm{cm}$, women $\geq 80 \mathrm{~cm}$, Japanese: $\mathrm{men} \geq 85 \mathrm{~cm}$, women $\geq 90 \mathrm{~cm}$.

Sagittal abdominal diameter has been proposed as an estimate of visceral adipose tissue, and it is seen in turn as being essential to clinical practice because it predicts cardiovascular and metabolic risks. Sagittal abdominal diameter showed the strongest correlation to visceral adipose tissue irrespective of age, sex, and the degree of obesity compared with other anthropometric measures [16].

There are powerful epidemiological associations between obesity and type 2 diabetes; together, overweight and obesity account for about two-thirds of cases of type 2 diabetes [17]. Furthermore, the prevalence of type 2 diabetes is increasing sharply in the population 50- 60 years of age and older as illustrated in Figure 1. A truncal distribution of body fat due to visceral fat accumulation confers the greatest risk of developing the disease. Furthermore, increased body weight is associated with increased death rates for all cancers combined and for cancers at multiple specific sites. The heaviest men and women (BMI of at least 40.0) in a large prospectively studied cohort had death rates from all cancers that were 52 per cent and 62 per cent higher, respectively, than the rates in men and women of normal weight [18]. In an American study it was forecasted that provided current obesity trends continue, the negative health effects on the US population will increasingly outweigh the positive effects gained from the declining rate of smoking [19]. In menopausal women obesity confers a lower risk of osteoporosis, probably due to combined effects of weight-bearing and aromatization of adrenal androgens to oestrogens affecting bone metabolism.

Since body weight is the most important determinant of bone density, intentional weight reduction or eating disorders such as anorexia nervosa confer an increased risk of osteoporosis, and bone loss may never recover completely even once weight is restored [20]. Also in postmenopausal women the negative impact of bone loss is not reversed when weight partially rebounds following the end of active intervention programs [21]

However, in a ten year prospective observational study on postmenopausal women, the health related risks of high BMI outweighed the protective effects of high BMI on bone mass, and weight gain increased the risk of hypertension, breast cancer and diabetes [22]. Furthermore, obesity was also related to an increased risk of several less life-threatening conditions such as osteoarthritis, chronic back pain and poor self-assessed health [22]

On the other hand, a low BMI is also often associated with an increased risk of mortality in seriously ill or hospitalized older adults [23], whereas a high BMI or overweight/obesity is more closely associated with chronic health conditions. There are some problems, however, that are associated with the use of BMI as an indicator of health and nutritional status in older 
adults including the difficulty of adjusting for loss of height with age and inability to get a true measure of height due to inability to stand or due to amputations [23].

Furthermore, CVD, arthritis, falls and fractures also reduce mobility [24]. While all these conditions can contribute to weight gain, they can also lead to unintentional weight loss (anorexia of ageing). The non-physiological causes of the anorexia of ageing include social (e.g. poverty, isolation), psychological (e.g. depression, dementia), medical and pharmacological factors. Physiological factors include changes in taste and smell, diminished sensory-specific satiety, delayed gastric emptying, altered digestion-related hormone secretion and hormonal responsiveness, as well as food intake-related regulatory impairments for which specific mechanisms remain largely unknown [25].

\section{Sarcopenia}

The term sarcopenia derives from the Greek terms "sarx" (meat) and "penia" (loss). Sarcopenia, defined as a syndrome rather than as a pathology, is the loss of muscle mass and function associated with normal aging. Although there has been an increasing interest in investigating the functional consequences and biologic mechanisms of sarcopenia, no international definition has been proposed to identify sarcopenic individuals [26]. The factors that contribute to the development of sarcopenia in the elderly are: the state of chronic inflammation, atrophy of motorneurons, reduced protein intake and immobility. Sarcopenia is associated with adverse clinical outcomes like mobility limitations, functional impairment and fractures. Patients with sarcopenic obesity are defined by high fat mass, and low muscle mass and are even more susceptible to mobility and disability problems than those who only have obesity or sarcopenia [27].

It has not been proven that elderly people who take nutritional supplements have an increase in muscle mass; however, sarcopenia has been shown to be present in all malnourished patients. In an overview of sarcopenia and age-related endocrine functions, Sakuma and Yamaguchi (28) mentioned myostatin inhibition, testosterone supplementation, IGF-1 as future treatment options. They also pointed out that treatment with ghrelin may ameliorate the muscle atrophy elicited by age-dependent decreases in growth hormone, and that ghrelin may be administered orally.

The practice of physical resistance exercise has been shown to improve muscle mass and strength in older adults [29], but is not always feasible in elderly subjects, and it is not yet known how long its effects last after it is discontinued.

In conclusion, weight-loss therapy that minimizes muscle and bone loss is recommended for older persons who are obese and who have functional impairments or metabolic complications that can benefit from weight loss [30]. Furthermore, exercise and physical activity can effectively prevent weight gain in older adults and postmenopausal women either in terms of weight loss or maintenance [31].

\section{Nutrition}

\section{Dietary recommendations}

It could be speculated that dietary habits reported by the oldest old could serve as a recommendation for the ageing population to remain in good health for many years. Studies from around the world, however, suggest that there is considerable heterogeneity in dietary patterns and nutritional status of centenarians. The studies indicate that BMI and nutritional status as indicated by circulating levels of antioxidant vitamins, vitamin B12, folate, 
homocysteine and $25(\mathrm{OH})$ vitamin $\mathrm{D}$ of centenarians are quite heterogeneous and influenced by region of residency and many of the demographic, dietary and lifestyle factors that influence nutritional status in other older adults. Thus, at this time it seems unlikely that there is one particular dietary pattern that promotes exceptional longevity [32].

However, low rates of CVD, observed during the 1950s and 1960s, in the Mediterranean basin launched the hypothesis of beneficial health effects from the Mediterranean type of diet. The Lyon Diet Heart Study has received much attention. In this trial, 605 patients who survived a first myocardial infarction were randomised to either a control or a Mediterranean diet [33]. The control group was advised to follow a "prudent diet". The trial was discontinued early due to the significant superiority of the Mediterranean diet shown by an interim analysis. Following publication of the initial results, the two groups were followed up for a mean of 4 years. The composite outcome, which factored in myocardial infarction, cardiovascular death, episodes of unstable angina, overt heart failure, stroke and pulmonary or peripheral embolism, was reduced by $70 \%$ in the group on the Mediterranean diet relative to the control group.

A recent systematic review concluded that a large number of observational studies throughout the world have shown that a high adherence to a Mediterranean type of diet is associated with reduced risk of CVD and some types of cancer in the elderly [34]. The beneficial effects on human health have been attributed to several surrogate markers including blood pressure, lipids, inflammation and oxidative stress levels and body fat. It seems that the high consumption of vegetables, fruits, legumes, nuts, cereals, olive oil, fish, together with moderate consumption of alcohol, predominantly wine, leads to a high ratio of monounsaturated-to-saturated fatty acids, a low intake of trans fatty acids and a high ingestion of dietary fiber, antioxidants, polyphenols and magnesium, all beneficial for human health [34].

The recently launched term "Nutrigenomics" refers to the new nutritional science in which researchers use high throughput tools to investigate interactions between nutrition and the genome and their consequences for gene expression, cell function and human health. Nutrigenomics aims to personalize or stratify dietary advice based upon modification of risk associated with genetic susceptibility to chronic diseases [35].

\section{Oxidative stress}

Oxidative stress increases with ageing [36] as it is involved in virtually all the diseases associated with obesity [37]. Obesity causes an increase of interleukin (IL) 1, IL-6, tumour necrosis factor, C-reactive protein, cholesterol and triglycerides, excessive hormone production (the renin-angiotensin system hormones) and insulin resistance. With advancing age, these aforementioned changes, in combination with the low antioxidant intake and physical activity, contribute to the exacerbation of the oxidative stress [37]. Moderate physical activity may generate mild oxidative stress that activates cellular stress response which signals and potentiates cellular antioxidant defence capacity whereas exhaustive exercise may cause accumulation of reactive oxygen species that can damage DNA, cause mutations or promote carcinogenesis (38).

Oxidative stress resulting from the overproduction of reactive oxygen species may play a role in aging and in the development of diabetes, some malignant diseases and other chronic diseases $[39,40]$. It is a deleterious process that results in damage to key cellular components such as DNA, lipids, and proteins [40]. The effects of oxidative stress are counteracted by several enzymatic and nonenzymatic antioxidant defence systems, with vitamin A, vitamin C, vitamin $\mathrm{E}$, and the carotenoids serving as important components of the primary nonenzymatic antioxidant defence system [41, 42]. 
Furthermore, in a prospective randomized double-blind placebo-controlled trial among Swedish citizens aged 70 to 88 years, it was shown that long-term supplementation of selenium and coenzyme Q10 reduced cardiovascular mortality [43].

\section{Vitamin B12}

Poor vitamin B12 status affects about $10-15 \%$ of older adults and is associated with both neurologic and hematologic disorders including sensory disturbances to the extremities, gait ataxia, cognitive impairment, mood changes, and anaemia [44, 45]. Risk factors for vitamin B12 deficiency include demographic, dietary and age-related health conditions including atrophic gastritis. The latter condition affects up to $30 \%$ of older adults, reduces the absorption of vitamin B12 from food and is the most common cause of vitamin B12 deficiency $[44,45]$.

\section{Vitamin D status}

Vitamin D is acquired through diet and skin exposure to ultraviolet B light. Skin production is determined by length of exposure, latitude, season, and degree of skin pigmentation. Vitamin $\mathrm{D}$ deficiency is common among moderately and heavily pigmented immigrants living in Europe and in Pakistani men living in Norway, serious vitamin D deficiency was prevalent, and five times as frequent as in native Norwegian men [46]. Furthermore, vitamin D deficiency is a risk for dark skinned children immigrated to countries far from the equator, like Denmark [47].

Poor vitamin D status has been associated with osteoporosis, falls, fractures, cardiovascular diseases, some cancers, autoimmune diseases and other age-related conditions [48-51]. Risk factors for poor vitamin D status include low cutaneous vitamin D synthesis due to limited sun exposure, living at higher latitude and increased skin pigmentation, and low intake from foods and supplements. Older individuals are at particular risk for vitamin D deficiency because of a reduced capacity to produce vitamin D precursors in the skin from UV light, limited sun exposure due to poor mobility or place of residence, and low intakes of vitamin D [51].

In conclusion, there may be a need for greater attention to lifestyle factors such as increased intake of vitamin D rich foods and supplements which may be an effective strategy for improving vitamin D status and associated function in centenarians.

\section{Caloric restriction}

Caloric restriction, decreasing caloric intake by 20-30\%, was first shown to extend life in rats nearly 80 years ago. Populations with an unusually high prevalence of centenarians all tended to be (or had been) very physically active, non-obese and small in stature, suggestive of some degree of caloric restriction. Thus, considerable interest has been shown in the ability of caloric restriction to improve multiple parameters of health and to extend lifespan.

Furthermore, many religions incorporate one or more forms of food restrictions or religious fasting periods as the Islamic Ramadan.

In summary, caloric restriction has been demonstrated to extend the maximal lifespan of a diverse group of species. This extension of life is maximized when: 1) the magnitude of caloric restriction is elevated to the highest possible value before inducing malnutrition and 2) the duration of caloric restriction is maximized [52]. Animals on caloric restriction regimens exhibit a variety of improvements in overall health in general and cardiovascular health in particular. Unfortunately, the likelihood of discovering whether or not caloric restriction extends human life is rather remote due to the ethical and logistic limitations of research design. The optimal magnitude and duration of caloric restriction for humans will also likely 
never be known for the same reason. Nevertheless, many human caloric restriction studies have noted favourable changes in biomarkers related to cardiovascular and glucose metabolism that may relate to longevity [52]. Although caloric restriction has many positive effects on health and longevity, quality of life on a restricted diet as well as the ability to maintain that diet long term are concerns that must be considered in humans [53].

\section{Physical fitness and physical activity}

Physical fitness can be translated as a state of well-being that allows one to meet the demands of daily living or that provides the basis for sport performance, or both [54]. Physical fitness appears to be similar to physical activity in its relation to morbidity and mortality but is more strongly related to health outcomes than physical activity [55]. Most analyses have shown at least a 50\% reduction in mortality among highly fit people compared with low fit people [54]. Physical fitness is dependent on numerous factors like nutritional status, dietary and smoking habits, genetics, socio-economic factors, and of course physical activity and exercise habits. Apart from dietary habits, nutrition, and abstaining from tobacco physical activity and exercise habits are factors which can be individually modified and thereby contribute to healthy ageing. In the following we will summarize the effects of physical activity and exercise on a number of metabolic phenomena and on mental as well as physical condition in the ageing population. Apart from several ways of retrieving self-reported data, physical activity levels may be measured and defined by pedometers that are simple and inexpensive sensors to asses and motivate physical activity behaviours in clinical practice. Based on currently available recommendations [56], pedometer-determined physical activity for adults can be classified in four groups: < 5000 steps/day ('sedentary'); 5000-7499 steps/day ('low active'); 7500-9999 steps/day ('somewhat active'); and $\geq 10000$ steps/day ('active'). A value of at least 10000 steps/day is gaining popularity in the media and appears to be a reasonable estimate of daily activity for apparently healthy adults [57] which roughly corresponds to a walking distance of seven kilometers. Furthermore, pedometer-determined physical activity may serve as a surrogate marker for inflammation and subclinical organ damage in middle aged patients with type 2 diabetes [58].

\section{Exercise, physical activity and general health}

Regular physical activity and physical fitness help to prevent chronic disease and reduce the risk of premature death and mortality [54]. People with moderate to high levels of physical activity have lower mortality rate than those with lower levels of activity. A literature review concluded that physical activity leads to lower utilization of healthcare services [59]. The causes of lower morbidity, use of health care and mortality in physically active people are probably multifold but some of them will be discussed below.

\section{Exercise, physical activity and cardiovascular effects}

Physical activity prevents cardiovascular disease (CVD) by means of effects on a number of risk factors for CVD. For example a meta-analysis showed significant decrease in blood pressure, body fat and triglycerides in groups of normotensive or prehypertensive adults by dynamic resistance training [60]. In a Cochrane review Orozco et al [61] concluded that exercise plus diet reduced risk of diabetes compared to standard recommendations and had favorable effects on weight, BMI, waist-to-hip-ratio, waist circumference, and systolic as well as diastolic blood pressure but only marginal effects on blood lipids. In patients with diabetes type 2 aerobic exercise alone or combined with resistance training improved glycemic control, systolic blood pressure, triglycerides and waist circumference according to a meta-analysis on relevant literature between 1970 -2009 [62]. During recent years sedentary behavior has 
appeared to be an important risk factor, probably at least as important as lack of exercise, for a number of diseases and mortality [63]. Apart from primary prevention of CVD, exercise is also used for rehabilitation after cardiac events. Exercise-based cardiac rehabilitation is associated with reduced mortality and re-infarction, probably even shorter programs improve long-term outcomes according to a review that identified 34 relevant Randomized Controlled Trials [64]. One mechanism seems to be reduced inflammatory activity induced by exercise in patients with coronary artery disease, and measured mainly as reduced C-reactive protein and fibrinogen [65]. Even after heart transplantation, exercise seems beneficial and improves oxygen consumption and muscle strength [66].

Physical activity and fracture risks: osteoporosis, balance and risk of falls. Osteoporosis leads to increased risk of skeletal fractures and is usually pharmacologically treated. A systematic Cochrane review published in 2011 examined the effectiveness of exercise in preventing bone loss and fractures in postmenopausal women [67]. They found a relatively small but statistically significant and possibly important effect of exercise on bone density but no effect on numbers of fractures. Still the authors concluded that exercise has the potential to be a safe and effective way to avert bone loss in postmenopausal women. Gomez-Cabello et al concluded in a systematic review that strength exercise is a powerful stimulus to improve and maintain bone mass during ageing [68] as well as multi-component exercise programmes of strength, aerobic, high impact and weight-bearing training. Walking provides only a modest increase in the load on the skeleton, and it therefore appears less effective in osteoporosis prevention than multi-component programs [68].

Fracture risk is not only dependent upon bone density but also on postural balance. Another systematic Cochrane Review selected randomized controlled trials testing the effects of exercise on balance in older people [69]. The review found weak evidence that some types of exercise improved clinical balance in older people but there was insufficient evidence that general physical activity like walking or cycling affects balance [69].

\section{Physical activity and mental health}

Windle and coworkers [70] reviewed studies on exercise in promoting mental health in older age (above 65 years). They found an overall effect of exercise on mental well-being when they included interventions designed for older sedentary people in a community setting. They also concluded a minimum of two sessions per week of at least 45 minutes duration each to induce effects. One possibly contributing factor to increased mental health could be the improved sleep quality that has been found in middle-aged and older adults with sleep problems during exercise [71].

Depression is a major global cause of impaired health and is usually treated by means of antidepressants and/or psychotherapy. However, exercise has been tried in a number of studies. A Cochrane review found 32 trials (1858 participants) where exercise had been compared with standard treatment, no treatment or placebo in adults [72]. The authors concluded that exercise seems to improve depressive symptoms in people with depression, compared to no treatment or control intervention, but suggested caution in interpreting the results because few studies were methodologically robust.

Depressive symptoms in patient with a chronic illness were found to be significantly reduced after exercise [73]. This was especially true in patients with mild to moderate depression and when function-related outcomes were improved by the exercise. Also depression in cancer survivors has been treated with exercise and a meta-analysis concluded that the effect on 
depression was modest [74]. The effects seemed larger when the exercise programs were supervised, not performed at home and lasted for more than 30 minutes per session [74].

\section{Physical activity and cancer}

Friedenreich and Orenstein analysed the association between physical activity and cancer prevention. Based on more than 250 epidemiological studies it was concluded that physical activity is convincingly associated with reduced risk of breast and colon cancer but possibly also contributes to a lower risk of endometrial, lung and prostate cancer [75]. Ballard-Barbas and co-workers from NIH, USA [76] concluded in a systematic review that there is consistent evidence that physical activity is associated with reduced breast and colon cancer-specific mortality in cancer survivors. For other kinds of cancer the evidence is still insufficient. According to a review of more than 300 publications, exercise had effects on improving several biomarkers implicated in breast and colon cancer pathways including insulin, leptin, oestrogens and apoptosis regulation [77]. In breast cancer survivors exercise affected biomarkers associated with prognosis including insulin-like growth factor axis proteins, insulin, inflammation and a large effect in enhancing immune function [77].

\section{Physical activity and menopausal hot flushes}

The first time that exercise was suggested to be related to menopausal symptoms was when we reported that vasomotor symptoms were less common in a group of women taking part in aerobic classes at least weekly than in women of the same age in the general population [78]. The rationale for this study was the theory that vasomotor symptoms are caused by instability in the hypothalamic thermoregulatory centre in turn due to lowering of hypothalamic opioids after menopause. Regular physical activity has namely been suggested to increase hypothalamic opioid activity and may therefore again stabilize thermoregulation. A number of cross sectional studies and a few intervention studies [78-81] have since then been reported and most of them suggest but do not prove that regular physical activity may decrease the risk of having vasomotor symptoms or reduce the symptoms. The recent Cochrane review concluded that existing studies provide insufficient evidence that exercise is an effective treatment for vasomotor menopausal symptoms, or whether exercise is more effective than hormone replacement therapy or yoga [81]. It may be added that the type of activity is probably essential in order to reduce vasomotor instability, at least if the opioid theory will prove to be correct, since strength training including large muscle groups is probably more effective in this respect than e.g. cardiovascular training.

\section{Physical activity; risks and side effects}

There are of course certain risks related to initiating regular exercise and overuse injuries have long been well known [82]. It should be emphasized that too rapid increase in intensity may result in elevated risk of overuse symptoms so exercise should be increased gradually with achievable short-term goals, both when it comes to intensity, frequency and duration [83]. According to Phillips and co-workers, setting obtainable goals results in a more pleasant, confidence-inspiring experience. Furthermore, graduated physical activity programs should be coupled with long-term goals, whereby small increments of progress contribute to long-term health [83]. Despite all the advantages there is a small risk of becoming dependent on/addicted to exercise; a potential problem that has to be more carefully investigated [84]. Long-term excessive sustained exercise may be associated with cardiovascular side effects like myocardial fibrosis with arrhythmias, diastolic dysfunction, and artery wall stiffening 
but these effects probably do not affect other than extreme athletes after long time exercising [85].

Health economy aspects of changing habits.

A modelling study made a literature review and modeled the cost impacts and health outcomes of six physical activity interventions, over the lifetime of the Australian population [86]. They analyzed programs that encourage use of pedometers, mass media-based community campaigns, internet-based intervention program, the general practitioner (GP) physical activity prescription program, GP referral to an exercise physiologist, and the program to encourage more active transportation. The authors concluded that, despite substantial variability in the quantity and quality of evidence on intervention effectiveness, and uncertainty about the long-term sustainability, it is highly likely that as a package, all six interventions could lead to substantial improvement in population health at a cost saving to the health sector. They also concluded that intervention programs that encourage use of pedometers and mass media-based community campaigns are the most cost-effective strategies to implement and are very likely to be cost-saving.

\section{Summary and conclusion}

The expected life span is increasing gradually and this confers a number of challenges. In order to spend the years of older age with optimal health there are a number of individual options that may be used including use of healthy dietary and exercise habits. Aiming at preventing obesity without malnourishment through the use of, for example, components from the Mediterranean type of diet is probably of value and is associated with reduced risk of CVD and some types of cancer, in the elderly. Exercise has been shown to prevent a number of health threatening diseases including CVD, a number of cancers as well as mental disturbances. To decrease a sedentary life style seems at least as important as regular exercise. For example, watching TV has been shown to decrease expected life time significantly, and on average, every single hour of TV viewed after the age of 25 reduces the viewer's life expectancy by 21.8 (95\% UI: 0.3-44.7) minutes [87]. Exercise could probably be tailored to increase cardiovascular health or to prevent bone loss. It is of great importance for health care providers to recommend slowly increased frequency, duration and intensity and to help find activities that suit the individual in order to increase compliance. Much research has to be made in order to find the ideal doses of exercise and to increase long-term adherence to the kind of exercise recommended. By all means dietary and exercise modifications seem to be strong promoters of healthy ageing.

\section{Practice points}

- Weight-loss therapy that minimizes muscle and bone loss is recommended for older persons who are obese and who have functional impairments or metabolic complications that can benefit from weight loss. 
- Exercise and physical activity can effectively prevent weight gain in older adults either in terms of weight loss or maintenance and may also prevent cardiovascular disease (CVD), osteoporosis, some malignant diseases and mental disturbances.

- High adherence to a Mediterranean type of diet is associated with reduced risk of CVD and some types of cancer, in the elderly.

- The avoidance of a sedentary life style seems at least as important as regular exercise in order to reduce the risk for cardiovascular disease.

\section{Research agenda}

- Exploring the evidence for tailored and individualized dietary recommendations and physical exercise in different medical conditions and at different stages of life. This includes for example the modes, frequency, and duration of physical exercise to be beneficial as primary or secondary prevention of different medical conditions.

- To obtain further knowledge from translational research on how to improve methods for long-term sustainability in favorable life style changes at both individual and community based levels.

- The impact from giving priority from society to implement evidence based methods both within the health care sector as well as in the general population for prevention of life style related medical conditions, reduced quality of life and reduced remaining expected life time.

\section{References}

1 World population projections: the 2000 revision. Population Division Department of Economic and Social Affairs, United Nations; http://www.un.org/ spanish/esa/population/wpp2000h.pdf [accessed 29.12.10] 2 World Health Organization. Active ageing: a policy framework; 2009. http://whqlibdoc.who.int/hq/2002/WHO NMH NPH 02.8.pdf [Accessed January 14, 2009] 3 Yusuf S, Hawken S, Ounpuu S, et al. Effect of potentially modifiable risk factors associated with myocardial infarction in 52 countries (the INTERHEART study): case-control study. Lancet 2004;364:937-52

4. von Deneen KM, Liu Y. Obesity as an addiction: Why do the obese eat more? Maturitas. 2011;68:342-5.

5. Craigie AM, Lake AA, Kelly SA, Adamson AJ, Mathers JC. Tracking of obesity-related behaviours from childhood to adulthood: A systematic review. Maturitas. 2011;70:266-84 6 Hedley AA, Ogden CL, Johnson CL, Carroll MD, Curtin LR, Flegal KM. Prevalence of overweight and obesity among US children, adolescents, and adults, 1999-2002. JAMA 2004;291:2847-50

7 Flegal KM,CarrollMD,Ogden CL, Johnson CL. Prevalence and trends in obesity among US adults, 1999-2000. JAMA 2002;288:1723-7

8 Gallagher D, Visser M, De Meersman RE, et al. Appendicular skeletal muscle mass: effects of age, gender, and ethnicity. J Appl Physiol 1997;83:229-39 
9 Beaufrere B, Morio B. Fat and protein redistribution with aging: metabolic considerations. Eur J Clin Nutr 2000;54(suppl):S48 -53

10 World health organization: global database on body mass index; 2010. http://apps.who.int/bmi/index.jsp?introPage=intro 3.html [accessed 13.12. 10] 11. Kanazawa M, Yoshiike N, Osaka T, Numba Y, Zimmet P, Inoue S. Criteria and classification of obesity in Japan and Asia-Oceania. Asia Pac J Clin Nutr 2002; 11 Suppl 8: S732-S737

12. Bei-Fan Z; Cooperative Meta-Analysis Group of Working Group on Obesity in China. Predictive values of body mass index and waist circumference for risk factors of certain related diseases in Chinese adults: study on optimal cut-off points of body mass index and waist circumference in Chinese adults. Asia Pac J Clin Nutr 2002; 11 Suppl 8: S685-93 13 Chan JM, Rimm EB, Colditz GA, Stampfer MJ, Willett WC. Obesity, fat distribution, and weight gain as risk factors for clinical diabetes in men. Diabetes Care 1994;17:961-9 14 de Koning L, Merchant AT, Pogue J, Anand SS. Waist circumference and waist-to-hip ratio as predictors of cardiovascular events: meta-regression analysis of prospective studies. Eur Heart J. 2007;28(7):850-6

15. Alberti KG, Zimmet P, Shaw J; IDF Epidemiology Task Force Consensus Group. The metabolic syndrome--a new worldwide definition. Lancet. 2005;366:1059-62

16 Yim JY, Kim D, Lim SH, Park MJ, Choi SH, Lee CH, Kim SS, Cho SH. Sagittal abdominal diameter is a strong anthropometric measure of visceral adipose tissue in the Asian general population. Diabetes Care. 2010;33:2665-70

17 Pickup JC and Williams G. Textbook of Diabetes (1), chapter 21.1. Blackwell Science Ltd, Oxford, UK 2003

18 Calle EE, Rodriguez C, Walker-Thurmond K, Thun MJ. Overweight, obesity, and mortality from cancer in a prospectively studied cohort of U.S. adults. N Engl J Med. 2003 24;348:1625-38.

19 Stewart ST, Cutler DM, Rosen AB. Forecasting the effects of obesity and smoking on US life expectancy. N Engl J Med 2009;361:2252-60

20 Mehler PS, Cleary BS, Gaudiani JL. Osteoporosis in anorexia nervosa. Eat Disord. 2011 Mar;19s:194-202.

21 Pines A. Weight loss, weight regain and bone health. Climacteric. 2012;15:317-19 22 Sirola J, Rikkonen T, Tuppurainen M, Honkanen R, Kröger H. Should risk of bone fragility restrict weight control for other health reasons in postmenopausal women?--A ten year prospective study. Maturitas. 2012;71:162-8

23 Neidert KC, Borner B. Nutrition care of the older adult: a handbook for dietetics professionals working throughout the continuum of care. 2nd ed. American Dietetic Association; 2004. p. 112-3

24 Wernette CM, White BD, Zizza CA. Signaling proteins that influence energy intake may affect unintentional weight loss in elderly persons. J Am Diet Assoc 2011;111:864-73 25 Hays NP, Roberts SB. The anorexia of aging in humans. Physiol Behav 2006;88:257-66 26 Messier V, Rabasa-Lhoret R, Barbat-Artigas S, Elisha B, Karelis AD, Aubertin-Leheudre M. Menopause and sarcopenia: A potential role for sex hormones. Maturitas. 2011;68:331-6 27 Burton AL, Sumukadas D. Optimal management of sarcopenia. Clin Interv Aging 2010;5:217-28

28 Sakuma K, Yamaguchi A. Int J Endocrinol. Sarcopenia and age-related endocrine function. 2012:127362. Epub 2012 May 28.

29 Liu CJ, Latham NK. Progressive resistance strength training for improving physical function in older adults. Cochrane Database Syst Rev 2009;(3):CD002759. 
30 Villareal DT, Apovian CM, Kushner RF, Klein S; American Society for Nutrition; NAASO, The Obesity Society. Obesity in older adults: technical review and position statement of the American Society for Nutrition and NAASO, The Obesity Society. Am J Clin Nutr. 2005 Nov;82(5):923-34

31. Stehr MD, von Lengerke T. Preventing weight gain through exercise and physical activity in the elderly: a systematic review. Maturitas. 2012;72:13-22

32 Hausman DB, Fischer JG, Johnson MA. Nutrition in centenarians. Maturitas. 2011;68:2039.

33. de Lorgeril M, Salen P, Martin JL, Monjaud I, Delaye J, Mamelle N. Mediterranean diet, traditional risk factors, and the rate of cardiovascular complications after myocardial infarction: final report of the Lyon Diet Heart Study. Circulation 1999;99:779-85

34 Tyrovolas S, Panagiotakos DB. The role of Mediterranean type of diet on the development of cancer and cardiovascular disease, in the elderly: a systematic review. Maturitas. 2010;65:122-30

35. Bergmann MM, Mathers JC. Ethical challenges in human nutrigenomics research. Maturitas. 2011;68:297-8

36 Oliveira BF, Nogueira-Machado JA, Chaves MM. The role of oxidative stress in the aging process. Sci World J 2010;10:1121-8

37 Vincent HK, Innes KE, Vincent KR. Oxidative stress and potential interventions to reduce oxidative stress in overweight and obesity. Diabetes Obes Metab 2007;9(6):813-39

$38 \mathrm{Na} \mathrm{HK}$, Oliynyk S. Effects of physical activity on cancer prevention. Ann NY Acad Sci 2011;1229; 176-83.

39 Ashok BT, Ali R. The aging paradox: free radical theory of aging. Exp Gerontol 1999;34:293-303

40 Valko M, Leibfritz D, Moncol J, Cronin MTD, Mazur M, Telser J. Free radicals and antioxidants in normal physiological functions and human disease. Int J Biochem Cell Biol 2007;39:44-84

41 Chong-Han K. Dietary lipophilic antioxidants: implications and significance in the aging process. Crit Rev Food Sci Nutr 2010;50:93-107

42 Mecocci P, Polidori MC, Troiano L, et al. Plasma antioxidants and longevity: a study on healthy centenarians. Free Radic Biol Med 2000;28:1243-8

43. Alehagen U, Johansson P, Björnstedt M, Rosén A, Dahlström U. Cardiovascular mortality and $\mathrm{N}$-terminal-proBNP reduced after combined selenium and coenzyme Q10

supplementation: A 5-year prospective randomized double-blind placebo-controlled trial among elderly Swedish citizens. Int J Cardiol. 2012 May 22. [Epub ahead of print] 44 Institute of Medicine. Dietary reference intakes for thiamin, riboflavin, niacin, vitamin B6, folate, vitamin B12, pantothenic acid, biotin, and choline. Food and nutrition board. National academy of sciences. Washington, DC: National Academy Press; 1998

45 Baik HW, Russell RM. Vitamin B12 deficiency in the elderly. Annu Rev Nutr 1999;19:357-77

46. Meyer HE, Falch JA, Søgaard AJ, Haug E. Vitamin D deficiency and secondary hyperparathyroidism and the association with bone mineral density in persons with Pakistani and Norwegian background living in Oslo, Norway, The Oslo Health Study. Bone. 2004;35:412-7

47. Beck-Nielsen SS, Jensen TK, Gram J, Brixen K, Brock-Jacobsen B. Nutritional rickets in Denmark: a retrospective review of children's medical records from 1985 to 2005 . Eur J Pediatr. 2009; 168:941-9.

48 Bischoff-Ferrari HA, Dawson-Hughes B, Willett WC, et al. Effect of vitamin D on falls: a meta-analysis. JAMA 2004;291:1999-2006 
49 Bischoff-Ferrari HA, Willett WC, Wong JB, Giovannucci E, Dietrich T, Dawson-Hughes B. Fracture prevention with vitamin D supplementation. A meta-analysis of randomized controlled trials. JAMA 2005;293:2257-64

50 Wang TJ, Pencina MJ, Booth SL, et al. Vitamin D deficiency and risk of cardiovascular disease. Circulation 2008;117:503-11

51 Johnson MA, Kimlin MG. Vitamin D, aging and the 2005 dietary guidelines for Americans, grand rounds. Nutr Rev 2006;64:410-21

52. Trepanowski JF, Canale RE, Marshall KE, Kabir MM, Bloomer RJ. Impact of caloric and dietary restriction regimens on markers of health and longevity in humans and animals: a summary of available findings. Nutr J. 2011;7;10:107

53. Roth LW, Polotsky AJ. Can we live longer by eating less? A review of caloric restriction and longevity. Maturitas. 2012;71:315-9

54 Warburton DE, Nicol CW, Bredin SS. Health benefits of physical activity: the evidence.

CMAJ 2006; 174:801-808

55 Erikssen G. Physical fitness and changes in mortality: the survival of the fittest. Sports

Med 2001; 31:571-6

56 Tudor-Locke C, Basset DR Jr. How many steps/day are enough? Preliminary pedometer indices for public health. Sports Med 2004; 34: 1-8

57. Iwane M, Arita M, Tomimoto S, Satari O, Matsumoto M, Myashita K, Nishio I. Walking 10,000 steps/day or more reduces blood pressure and sympathetic nerve activity in mild essential hypertension. Hypertens Res 2000; 23: 573-80

58. Jennersjö P, Ludvigsson J, Länne T, Nyström FH, Ernerudh J, Östgren CJ. Pedometerdetermined physical activity is linked to low systemic inflammation and low arterial stiffness in patients with type 2 diabetes. Diabetic Medicine 2012;29:1119-25

59. Nazmi S. Exercise, physical activity and healthcare utilization: A review of literature for older adults. Maturitas 2011;70:285-289

60. Cornelissen VA, Fagard RH, Coeckelberghs E, Vanhees L. Impact of resistance training on blood pressure and other cardiovascular risk factors: a meta-analysis of randomized controlled trials. Hypertension 2011; 58(5):950-958

61. Orozco LJ, Buchleitner AM, Gimenez-Perez G, Rogué I, Figuls M, Richter B, Mauricio D. Exercise or exercise and diet for preventing type 2 diabetes mellitus. Cochrane Database Syst Rev, 2008, Jul 16;(3):CD003054

62. Chudyk A, Petrella RJ. Effects of exercise on cardiovascular risk factors in type 2 diabetes: a meta-analysis. Diabetes Care 2011;34:1228-1237

63. Thorp AA, Owen N, Neuhaus M. Dunstan DW. Sedentary behaviors and subsequent health outcomes in adults: a systematic review of longitudinal studies 1996-2011. Am J Prev Med. 2011;41:207-215

64. Lawler PR, Filion KB, Eisenberg MJ. Efficacy of exercise-based cardiac rehabilitation post-myocardial infarction: a systematic review and meta-analysis of randomized controlled trials. Am Heart J. 2011;162(4):571-584 
65. Swandfager W, Herrmann N, Cornish S, Mazereeuw G, Marzolini S, Sham L, Lanctot KL. Exercise intervention and inflammatory markers in coronary artery disease: a metaanalysis. Am Heart J. 2012;163(4):666-676

66. Hsieh PL, Wu YT, Chao WJ. Effects of exercise training In heart transplant recipients: a meta-analysis. Cardiology. 2011;120(1):27-35

67. Howe TE, Dawson LJ, Downie F, Murray A, Ross C, Harbour RT, Caldwell LM, Creed G. Exercise for preventing and treating osteoporosis in postmenopausal women. Cochrane Database Syst Rev 2011;July 6 (7):CD000333

68. Gomez-Cabello A, Ara I, Gonzalez-Aguero A, Casajus JA, Vicente-Rodriguez G. 2012; Sports Med 2012;42:301-25

69. Howe TE, Rochester L, Neil F, Skelton DA, Ballinger C. Exercise for improving balance in older people. Cochrane Database Syst Rev 2011, Nov 9 (11): CD004963.

70. Windle G, Hughes D, Linck P, Russell I, Woods B. Is exercise effective in promoting mental well-being in older age? A systematic review. Aging Ment Health. 2010 Aug;14(6):652-69.

71. Yang PY, Ho KH, Chen HC, Chien MY. Exercise training improves sleep quality in middle-aged and older adults with sleep problems: a systematic review. J Physiother. 2012;58(3):157-63.

72. Rimer J, Dwan K, Lawlor DA, Greig CA, McMurdo M, Morley W, Mead GE. Exercise for depression. Cochrane Database Syst Rev. 2012 Jul 11;7:CD004366

73. Herring MP, Puetz TW, O'Connor PJ, Dishman RK. Effect of exercise training on depressive symptoms among patients with a chronic illness: a systematic review and metaanalysis of randomized controlled trials. Arch Intern Med. 2012 Jan 23;172(2):101-11.

74. Craft LL, Vaniterson EH, Helenowski IB, Rademaker AW, Courneya KS. Exercise effects on depressive symptoms in cancer survivors: a systematic review and meta-analysis. Cancer Epidemiol Biomarkers Prev. 2012 Jan;21(1):3-19. Epub 2011 Nov 8.

75. Friedenreich CM, Orenstein MR. Physical activity and cancer prevention: etiological evidence and biological mechanisms. J Nutr 2002;132:3456S-3464S

76. Ballard-Barbash R, Friedenreich CM, Courneya KS, Siddiqi SM, McTiernan A, Alfano CM. Physical activity, biomarkers and disease outcomes I cancer survivors: a systematic review. J Natl Cancer Inst 2012;104:815-40

77. Winzer BM, Whiteman DC, Reeves MM, Paratz JD. Physical activity and cancer prevention: a systematic review of clinical trials. Cancer Causes Control 2011;22:811-26

78. Hammar M, Berg G and Lindgren R. Does physical exercise influence the frequency of postmenopausal hot flushes? Acta Obstetricia et Gynecologica Scandinavia, 1990, 69;409-412 
79. Ivarsson T, Spetz A-C, Hammar M. Physical exercise and vasomotor symptoms in postmenopausal women. Maturitas 1998; 29; 139-46.

80. Lindh-Åstrand L, Nedstrand E, Wyon Y, Hammar M. Vasomotor symptoms and quality of life in previously sedentary postmenopausal women randomised to physical activity or estrogen therapy.

Maturitas. 2004;48:97-105.

81. Daley A, Stokes-Lampard H, Macarthur C. Exercise for vasomotor menopausal symptoms. Cochrane Database Syst Rev. 2011 May 11;(5):CD006108.

82. Matheson GO, Macintyre JG, Taunton JE, Clement DB, Lloyd-Smith R. Musculoskeletal injuries associated with physical activity in older adults. Med Sci Sports Exerc. 1989;21:37985.

83. Phillips EM, Schneider JC, Mercer GR. Motivating elders to initiate and maintain exercise. Arch Phys Med Rehabil. 2004;85(7 Suppl 3):S52-7.

84. Berczik K, Szabó A, Griffiths MD, Kurimay T, Kun B, Urbán R, Demetrovics Z. Exercise addiction: symptoms, diagnosis, epidemiology, and etiology. Subst Use Misuse. 2012 Mar;47(4):403-17.

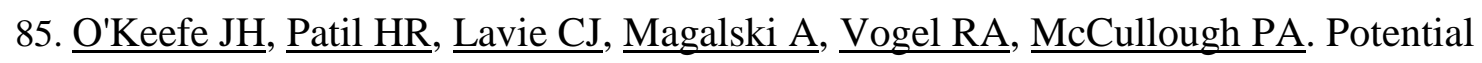
adverse cardiovascular effects from excessive endurance exercise. Mayo Clin Proc. 2012;87(6):587-95.

86. Cobiac LJ, Vos T, Barendregt JJ. Cost-effectiveness of interventions to promote physical activity: a modelling study. PLoS Med. 2009 Jul 14;6(7):e1000110. Epub 2009 Jul 14

87. Veerman JL, Healy GN, Cobiac LJ, Vos T, Winkler EA, Owen N, Dunstan DW. Television viewing time and reduced life expectancy: a life table analysis. Br J Sports Med. 2012;46:927-30. 


\section{Legends to Figure 1}

Prevalence of diabetes by age categories in the county of Östergötland, Sweden 2004 (n= 19 226)

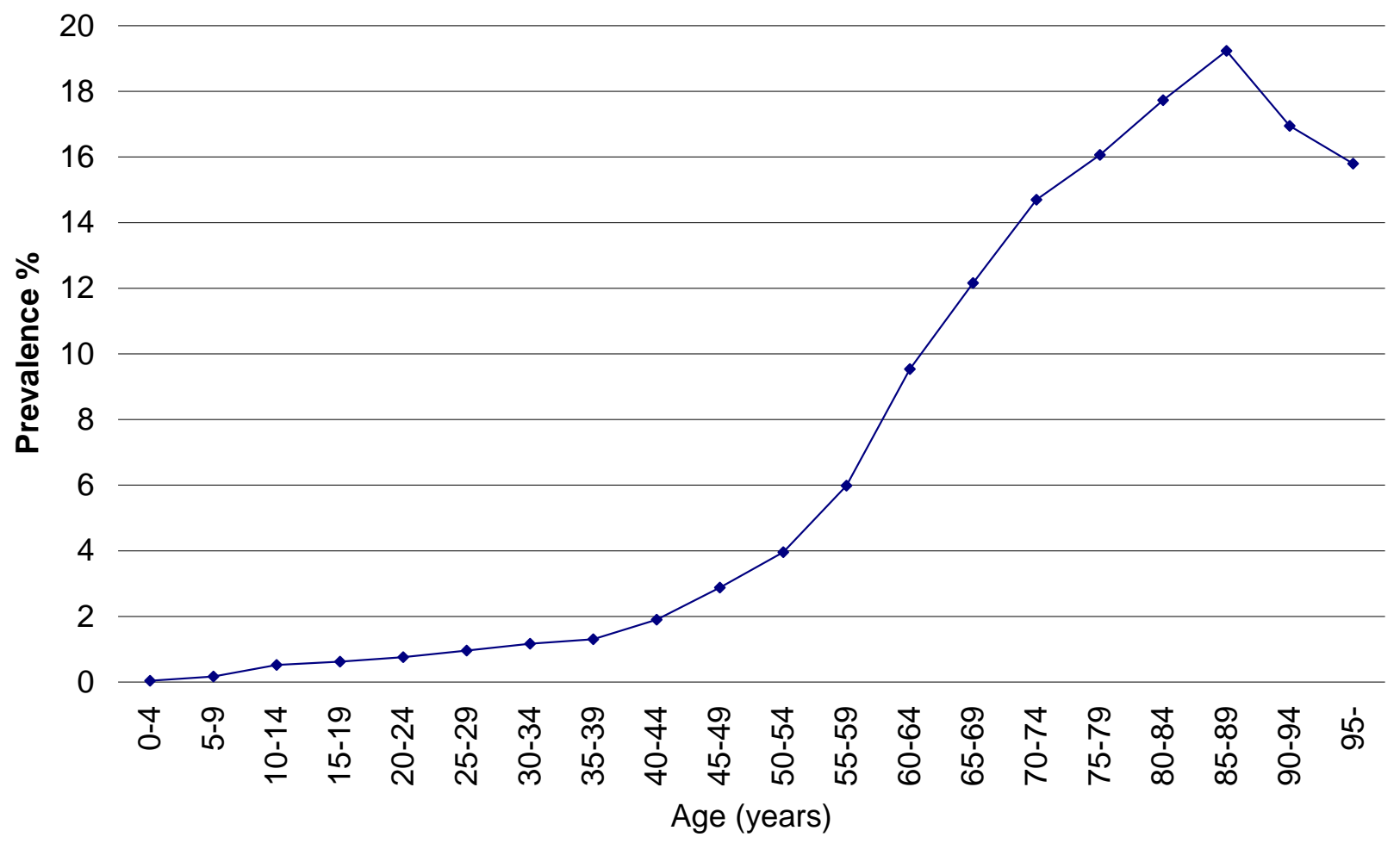

